\title{
A RARE MORBID CONDITION OF THE URINARY BLADDER (FIBROMYOMATOUS CHANGE).
}

\author{
By T. K. Monno, M.A., M.B., Assistant Physician to the Royal Infirmary \\ and Pathologist to the Victoria Infirmary, Glasgow.
}

\section{(Plate XII.)}

THE following case is of interest, chiefly on account of the remarkable appearance presented by the wall of the urinary bladder, the condition being, probably, of congenital origin.

The patient, a commercial traveller, æt. 29, was admitted to the Victoria Infirmary, under Mr. Maylard, on the 21st February, 1893. He complained of pain and difficulty in micturition. From early life, he had to strain while emptying his bladder. Ten years before admission, he had a slight illness (supposed to be due to hepatic disturbance) associated with a high colour of the urine, which threw down a sediment on standing. He afterwards went to Wales for a holiday, and while there, injured his left buttock.

The illness for which he now sought advice began 2 years before, the complaint being of severe pain in the left lumbar region, passing downwards to the left groin and testicle, and accompanied by sickness and vomiting. These symptoms would pass off after 2 or 3 days, to recur after an interval varying from 10 days to a month. In the early part of the illness, clotted blood was observed to be present in the urine for 2 or 3 days. In spite of his ill-health, the patient continued to attend to his business. There was nothing worthy of note in the family history.

On admission, a hard, tender swelling, dull to percussion, was found in the lower part of the abdomen. There was also a sense of tumour in the left lumbar and iliac regions; and at the upper part of this tumour there was felt a hard, egg-shaped body, which could be rolled under the fingers, Another and more superficial body was detected in the same neighbourhood.

The urine was decomposing and contained abundant albumen; but no tube casts or blood corpuscles were observed. There seems to have been no difficulty whatever in passing an instrument into the bladder.

As this case is recorded on the ground of its morbid anatomy, and not on account of its clinical features, it may be briefly stated that, in the course of an operation undertaken to relieve the symptoms, it was 
deemed advisable to excise the bladder altogether. The operation was a tedious one, as the ureters-to mention only one disturbing element -were so much dilated as to resemble small intestines; and when these were cut across they poured out a huge volume of urine into the wound. The patient died 5 hours afterwards.

A complete post-mortem examination was not made, but the following structures were removed and given to me for investigation :-

1. The bladder, with

2. Certain bodies seated on its upper end;

3. The kidneys and ureters; and

4. Two isolated tumours said to have been connected with the pelvis.

(1) The bladder was greatly enlarged, and its wall was much thickened. The inner surface of the organ suggested the appearance of a lobulated kidney, but the lobules were irregular in shape and size, some being very large. The depressions between the lobules were almost $\frac{1}{2}$ in. deep; whilst one such-situated to the left of the trigone-reached actually to a depth of more than $1 \frac{1}{2}$ in. below the general surface. The lobules-as regards their surface-were of a reddish-brown colour, with a tint of blue, but numerous white patches were seen upon them; these consisted of flakes of epithelium, and were easily detachable.

The lobules, or elevations of the mucous surface, were found on microscopic examination to consist of unstriped muscle and of connective tissue elements. There was, moreover, an abundant infiltration of round cells, which, at some parts, were collected in such numbers as to suggest the commencement of small abscesses. This last-mentioned appearance may perhaps be connected with the desquamation or loss of epithelium already alluded to.

(2) The bodies on the upper end of the bladder presented, to the naked eye, the appearance of convoluted rolls or worms embedded in fibrous tissue. Microscopically, they were found to consist largely of unstriped muscular fibres. Thus, one of the rolls cut across might show an investment of unstriped fibres coursing round it in a ring, the central portion or axis of the roll being constituted by similar fibres running in the direction of its length. These rolls also contained fibrous tissue and numerous capillaries. In some places, branched cells of irregular form could be seen ; also cells resembling epithelium, but devoid of any apparent nucleus.

(3) The kidneys and ureters were such as are seen in fully developed hydronephrosis. The left kidney was $8 \mathrm{in}$., and the right 6 in. in length. On the left side, two ureters passed down from the kidney to the bladder. These were at first quite separate, but they became united to one another halfway down, though the lumen of each remained distinct from that of the other throughout its whole length, and the two opened by separate orifices into the bladder. The right ureter was single. All three ureters were much dilated, and measured, at parts, when lying flat on the table, more than $1 \frac{1}{2}$ in. across.

(4) The two tumours connected with the pelvis were typical hard fibromata. They measured about 2 and 3 in. in length respectively. Each was ovoid in form, with a distinct capsule, and varied in hardness in different parts. The cut surface was white and glistening, and the microscopic appearances were those of fibrous tissue with abundant spindle shaped nuclei and occasional blood vessels.

REMARKs.-There can be little doubt, I think, that this abnormality of the bladder wall was of congenital origin, though probably, like a nævus, it may have been a slight thing at the time of birth, and may have developed greatly as the patient grew up. The hydronephrosis

10-JL. OF YATH. - vos. III. 
was no doubt due to the condition of the bladder. One of the large lobules on the inner surface of the organ corresponded closely in situation to the trigone. One ureter opened to the right of this; the two others to the left. The orifice of one of these latter was situated deeply on the side wall of the very deep interlobular furrow described above. Obviously, therefore, the ureters would be continually liableprobably continually subject-to very considerable pressure, as they passed through this great thickness of bladder wall. The pressure on the ureters, and the consequent obstruction to the flow of urine, would become all the greater, if, as is likely, the increase in thickness of the wall was progressive.

The condition of the bladder, the existence of two ureters on the left side, the convoluted bodies on the upper end of the bladder, and the two fibromata, are four facts which together point to a strong tendency to abnormality in the body of this individual; while the clinical history seems to show that the malformation of the bladder had already begun to produce its effects in early life. We must, therefore, suppose that the hypertrophy was of congenital origin, or due to a congenital tendency.

Owing to the incomplete nature of the autopsy, or more probably to a regrettable oversight, there is no record of the urethra having been specially examined after death, with a view to ascertain whether it presented any condition likely to cause obstruction to the outflow of urine. But, as has been already stated, there seems clearly to have been no obstruction to the passage of a catheter into the bladder during life. While, therefore, it is conceivable that there may have been some abnormal structure of a valvular character, interfering with the emission of urine, it appears to me that a theory of this kind is not required to explain the facts, which may quite well be accounted for by the state of the bladder itself.

Fibromata and myomata are very uncommon in connection with the bladder, and, when they do occur, take the form of more or less definite tumours. In this case, however, there was what might be termed a fibromyomatous change, involving the bladder wall generally, but showing chiefly on its mucous surface. I have consulted a large number of the most authoritative works on diseases of the bladder, but have been unable to find any record of anything similar to what has been here described.

My thanks are due to Mr. Maylard for his kind permission to publish this case, and for information with regard to its clinical aspects.

\section{DESCRIPTION OF PLATE XII.}

Frg 1.-Kidneys and ureters. The right kidney is cut open; the left gives origin to two ureters.

Fig. 2.-Bladder cut open in front. (Unfortunately the original negative taken from the fresh specimen went amissing in the engraver's hands. The present illustration was obtained from a negative taken from a water-colour drawing.) The lobulated character of the inner surface of the organ is seen; also the greatly thickened wall, and the orifices of two of the ureters. 

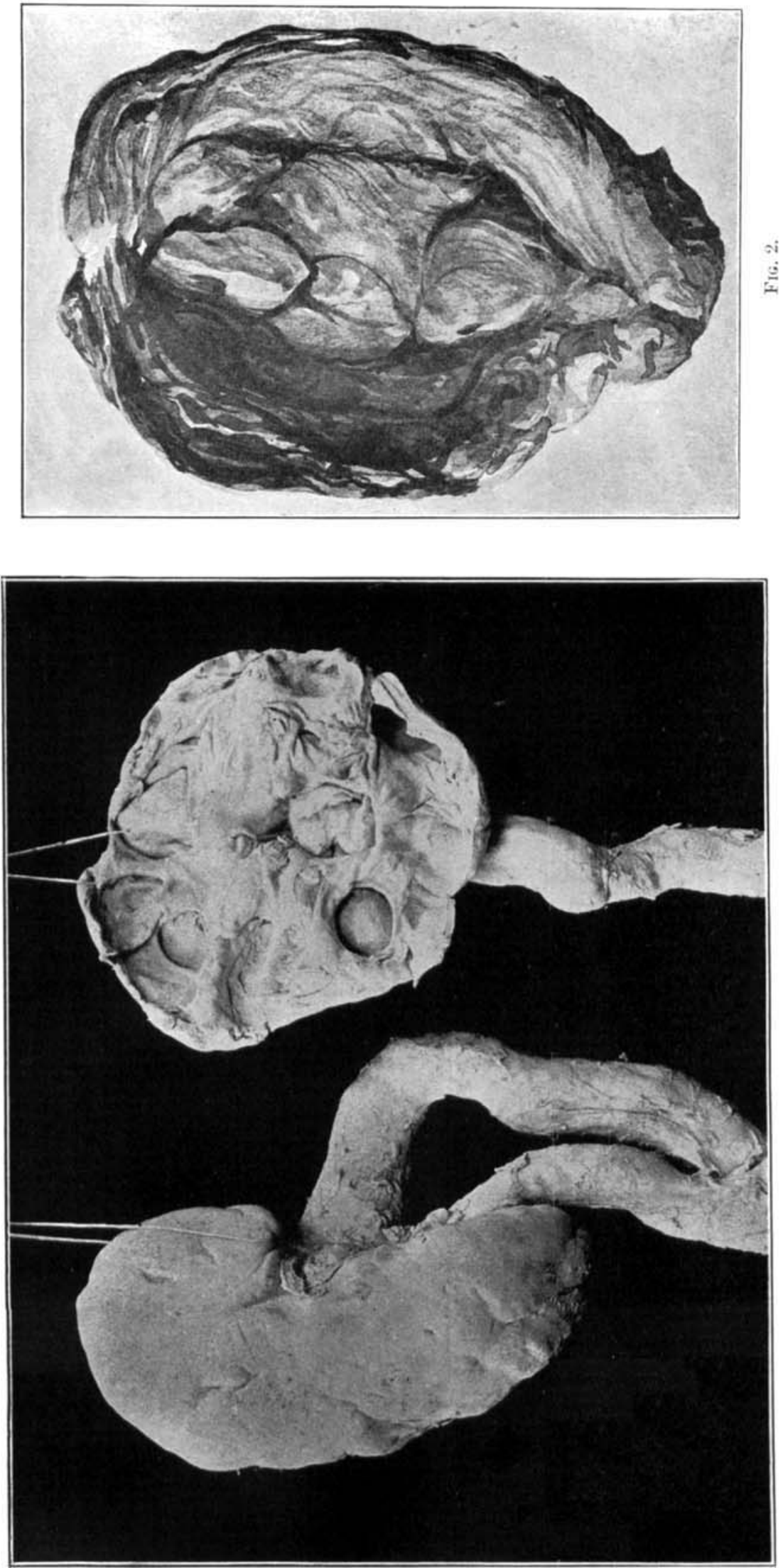

运 